\title{
sciendo
}

\section{LoAn to VAlue RATio AND Monetary Transmission MECHANISM}

\author{
Vlastimil Reichel $^{1}$, Daniel Němec ${ }^{2}$, Jakub Chalmovianský $^{3}$
}

\begin{abstract}
Using a dynamic stochastic general equilibrium model (DSGE) with the housing sector, this paper evaluates the impact of housing collateral on the business cycle in the Czech economy. We devote special attention to the setting of the loan to value (LTV) ratio, which we believe plays an important role as a regulator of the monetary transmission mechanism. The impacts of LTV ratio are quantified by simulating the responses of alternative LTV level setting on key macroeconomic variables. Our simulations are based on an estimated DSGE model. Our approach allows us to understand better the responses of the real economy to the tightening of monetary policy moderated by different LTV levels. Our results show that higher loan to value ratios strengthen the effect of the monetary transmission mechanism to consumption and output.
\end{abstract}

\section{Keywords}

Housing Sector, Loan to Value Ratio, DSGE Model, Monetary Transmission Mechanism, Czech Republic

\section{Introduction}

The real estate market has recently been associated with the terms of financial stability and macroprudential policy. The roots of this combination can be found in the US mortgage crisis and the real estate market crisis in Spain, Hong Kong, or New Zealand. Although the situation in the Czech Republic does not fully correspond to the previous cases, the attractiveness of this topic has recently become apparent (by the public and experts).

The Czech National Bank has a variety of traditional instruments, which can correct what is happening in the markets related to the financial sector to fulfil its commitment to financial stability. One of them is open market operations resulting in changes in interest rates, which will be reflected in the whole economy using the monetary transmission mechanism. Also, there has been a recent effort by the central bank to correct mortgage

\footnotetext{
${ }_{1}^{1}$ Masaryk University, Lipová 41a, Brno, Czech Republic. E-mail: reichel.v@mail.muni.cz.

${ }^{2}$ Masaryk University, Lipová 41a, Brno, Czech Republic. E-mail: daniel.nemec@econ.muni.cz.

${ }^{3}$ Masaryk University, Lipová 41a, Brno, Czech Republic. E-mail: chalmoviansky@mail.muni.cz.
} 
lenders through various recommendations or regulations regarding optimum ratio settings, such as the Loan-to-Value ratio (LTV). The LTV indicator expresses the ratio between the loan granted and the value of the mortgaged property. However, LTV is also a tool that can cause frictions in the financial markets and thus significantly affect the monetary transmission mechanism. It is in the context of this mechanism that targeted LTV settings can become a useful central bank tool to reduce systemic risks. Systemic risks include: (i) prevent excessive accumulation of risks due to external influences and market failures and thus help smooth the financial cycle over time (time effect); (ii) ensure greater resilience of the financial sector and reduce the effect of contagion among banking entities (crosscutting effect); (iii) promote a systemic approach to financial regulation in order to create an appropriate set of incentives for market participants (structural effect). This should be part of the macro-prudential strategy as defined by the European Central Bank (ECB, 2019).

This work aims to quantify the regulatory impact of LTV settings on the monetary transmission mechanism in the Czech Republic. Dynamic stochastic general equilibrium (DSGE) model will be used to achieve this goal. The DSGE model will include, in addition to the standard parts typical of this type of model, a mechanism through which part of the household sector satisfies its consumption through real estate collateral. Based on the identified model on Czech data, we simulate the effects of alternative LTV settings on crucial macroeconomic variables and macroeconomic stability.

\section{Literature}

The basic idea of DSGE modelling of credit constraints in the housing market was recorded by Iacoviello (2005). Iacoviello (2005) created and estimated on the US data a small DSGE model of a closed economy with credit and collateral constraints linked to property value. Following the work of Kiotak and Moore (1997), Iacoviello divided the household sector into patient households (without credit constraints) and impatient households (with credit constraints).

Other authors followed the concept of the DSGE model with the credit constraint mechanism as established by Iacoviello (2005). The models of closed economies include mainly the models: Bracons and Rabanal (2010), Iacoviello and Neri (2010), Kannan, Rabanal and Scott (2012), Guerrieri and Iacoviello (2017), Tonner and Brůha (2014) and Hloušek (2016). Open economy models include Christensen, Corrigan, Mendicino and Nishiyama (2016), Robinson and Robson (2012), Funke and Paetz (2012), or Funke, Kirkby and Mihaylovski (2018). Not all these works are typically associated with discussing the impact of monetary shocks when choosing an alternative LTV setting. However, they can provide a useful framework for critical evaluation of the results of this modelling approach, as they provide a relatively comprehensive view of the development and modification of the Iacoviello DSGE model (2005) over time.

DSGE models based on the work of Iacoviello (2005) typically focus on the impact of the rise in property prices and the subsequent shocks associated with this increase that the modelled economy faces. The most frequently mentioned effects of wealth resulting from the rise in property prices (as one of the sources of wealth of households) with the 
consequent increase in consumption. Typical works describing this effect are Iacoviello (2005), Bracons and Rabanal (2010), Christensen, Corrigan, Mendicino and Nishiyama (2016), or Robinson and Robson (2012).

Among the works focusing on the modelling of the wealth effect in the Czech economy, we can mention the works of Hloušek (2016) and Tonner and Brůha (2014). Interestingly, these works attribute a relatively negligible impact on the rest of the modelled economy. Tonner and Brůha (2014) even find that the effect of wealth on the business cycle of the Czech economy is weak, and therefore, even the monetary policy implications of property price fluctuations are not significant. On the other hand, these authors show that the DSGE model with implemented housing sector generally achieves better predictive capabilities. It is characteristic of the above work that the reader offers a very in-depth discussion of the impact of restrictive monetary policy in the environment of the models identified on the data of the examined economy. Most papers conceive this topic through comparison with benchmark impulse responses based on parameterization obtained from estimates of the estimated model. A more exciting approach was taken by Guerrieri and Iacoviello (2017), who were the first (in the model type Iacoviello (2005)) to discuss the use of non-linear simulations of the impact of credit constraints from the estimated model. The results were simulations that made it possible to observe the various impacts of shocks depending on whether it was a rise or fall in property prices.

Kannan, Rabanal and Scott (2012) have been investigating the use of LTV on the monetary transmission mechanism to address the use of alternative monetary rules in the credit constraint regime. Iacoviello and Neri (2010) started on the US economic data to discuss LTV's impact on the monetary transmission mechanism. They were later followed by Walentine (2014) and Hloušek (2016). Walentine (2014) and Hloušek (2016) using the core model of Iacoviello and Neri (2010) measured the impact of LTV size on the macroeconomic variables of the Swedish and Czech economies by simulating monetary shocks. Methodologically, the procedure of Iacoviello and Neri (2010), Walentine (2014) and Hloušek (2016) will be used in this paper as well.

Current literature focuses on the discussion of macroprudential policy. Mendicino and Punzi (2014) use counter-cyclical LTVs as an example of how monetary policy can react and smooth household consumption through business cycles. Funke, Kirkby and Mihaylovski (2018) show that lowering the LTV level allows lower real estate price growth during periods of boom.

\section{Model}

In our work is followed the model Iacoviello (2005), which belongs to the group of smaller DSGE models. Due to the range of complexity of the description of the whole model, only selected equations that are essential for understanding the key parameters and represent significant modifications compared to standard DSGE models will be presented. For a more detailed description of the model, see Iacoviello (2005). The model consists of four sectors: infinitely long-lived households and entrepreneurs, retailers, and the central bank (see Figure 1). Households are divided into two types: patient and impatient. Patient households offer work and capital, accumulate real estate, and demand final goods 
(consume). Also, they provide funding to businesses and impatient households. Impatient households also offer work, accumulate real estate and demand final goods (consume), but are credit constrained. Entrepreneurs demand labour and capital and combine it with real estate, which they can pledge and obtain credit to produce homogeneous intermediate goods. Credit constraints also limit entrepreneurs and the amount of their loans depends on the value of the real estate, as in impatient households. Retailers buy homogeneous intermediate goods, which they then sell at a surcharge as a competitive monopoly market. Retailers are price-makers and thus a source of nominal rigidities. These rigidities are captured at the aggregate level in the form of a Novokeynesian Phillips curve. The central bank sets the interest rate according to the Taylor rule with the smoothing of the interest rate and weighted only by the amount of inflation.

\section{Figure 1: Model structure}

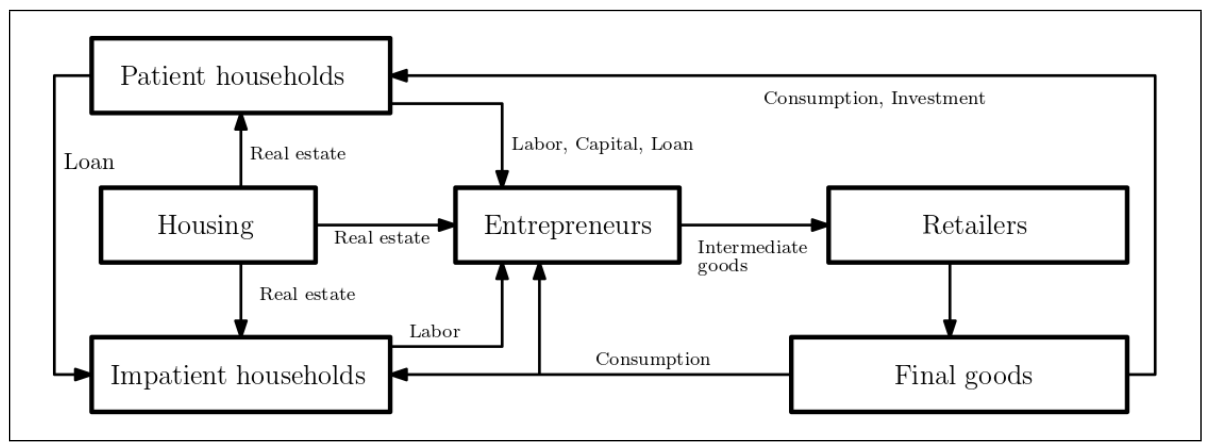

Source: Own construction

The household sector consists of patient (indexed $i=1$ ) and non-patient households (indexed $i=2$ ). Households maximize the utility function

$$
E_{0} \sum_{t=0}^{\infty} \beta_{i}^{t}\left(\ln c_{i, t}+j_{t} \ln h_{i, t}-\left(L_{i, t}\right)^{\eta} / \eta+\chi \ln \left(M_{i, t} / P_{i, t}\right)\right),
$$

where $E_{0}$ is the expectation operator, $\beta_{i} \in(0,1)$ is the discount factor, with $\beta_{1}>\beta_{2}$, guaranteeing a balance in which impatient households will be constrained by credit constraints (thus cannot act as lenders), $c_{i, t}$ is the aggregate consumption index, $h_{i, t}$ denotes the volume of property held, $L_{i, t}$ is the hours worked, $j_{t}$ represents a random change in marginal property holding that directly affects real estate demand and $M_{i, t} / P_{i, t}$ denotes real money balances. They maximize this utility through budget constraints

$$
c_{i, t}+q_{t} \Delta h_{i, t}+\frac{R_{t-1} b_{i, t-1}}{\pi_{t}}=b_{i, t}+w_{i, t} L_{i, t}+F_{t}+T_{i, t}-\Delta M_{i, t} / P_{t}
$$

where $\pi_{t}=P_{t} / P_{t-1}$ is inflation, $Q_{t} / P_{t}=q_{t}$ is the real housing price (value of the real estate), $W_{i, t} / P_{t}=w_{i, t}$ is the real wage, $T_{i, t}$ are net transfers from the central bank and $F_{t}$ are lump-sum profits from retailers that goes only to patient households. Let us also 
assume that patient households provide loans that can be recorded in real terms by help $-b_{i, t}$, where $b_{i, t}=B_{i, t} / P_{t}$, or they borrow and get back $-R_{t-1} B_{i, t-1} / P_{t}$ from a loan that was in the last period. The optimization problem would be the same for both households, without the credit constraint faced by impatient households. The credit constraint could be written in the form

$$
b_{t} \leq m_{2, t} E_{t}\left(q_{t+1} h_{2, t} \pi_{t+1} / R_{t}\right) .
$$

The expression $E_{t}\left(\frac{q_{t+1} h_{2, t} \pi_{t+1}}{R_{t}}\right)$ describes the expected value of the property and $m_{2}$ represents the LVT of impatient households. The parameter $m_{2}$ takes values from 0 to 1 , with 1 indicating that the household receives the full value of the property from the loan by collateral; 0 then indicates that even if the property is of any value, banks are not willing to provide credit for the collateral - households are therefore excluded from the financial market at $m_{2}=0$.

The second agent in the model are entrepreneurs producing intermediate goods using technology represented by a production function with three inputs: labour, capital and real estate.

$$
Y_{t}=A_{t} K_{t-1}^{\mu} h_{t-1}^{v} L_{1, t}^{\alpha(1-v-\mu)} L_{2, t}^{(1-\alpha)(1-v-\mu)} .
$$

In this equation, variable $A_{t}$ denotes the level of technology, $h_{t}$ is the input of real estate, $L_{1, t}$ and $L_{2, t}$ represents the work of patient and impatient households, $K_{t}$ is capital and $\alpha$ denotes the relative share of patient households. The parameters $v$ and $\mu$ indicate the proportion of real estate and capital. In addition to the production of intermediate products, entrepreneurs also consume. Representative entrepreneur maximizes utility function $E_{0} \sum_{t=0}^{\infty} \gamma^{t} \ln c_{t}$ due to budget and credit constraints given by relationships

$$
\begin{aligned}
\frac{Y_{t}}{X_{t}}+b_{t} & =c_{t}+q_{t} \Delta h_{t}+\frac{R_{t-1} b_{t-1}}{\pi_{t}}+w_{1, t} L_{1, t}+w_{2, t} L_{2, t}+I_{t}+\xi_{K, t}, \\
b_{t} & \leq m E_{t}\left(q_{t+1} h_{t} \pi_{t+1} / R_{t}\right),
\end{aligned}
$$

where the most important for us is again the parameter $m$, which indicates LTV of entrepreneurs.

Retailers in the model provide rigid prices. Thanks to price rigidity, it is possible to define a forward-looking Phillips curve that expresses the positive dependence of inflation on expected inflation and a mark-up to marginal costs. The behaviour of the central bank is described by the Taylor rule, which has the following expression in a non-linear form

$$
R_{t}=\left(R_{t-1}\right)^{r_{R}}\left(\pi_{t-1}^{1+r_{\pi}}\left(Y_{t-1} / Y\right)^{r_{Y}} \overline{r r}\right)^{\left(1-r_{R}\right)} e_{R, t} .
$$

The Iacoviello Model (2005) has a unique stationary balance in which impatient households and entrepreneurs are limited by credit and are taking a credit up to their limit. The balance is understood as the allocation of values that meet the model equations under the conditions of cleaning the labour market, $\left(L_{t}=L_{1, t}+L_{2, t}\right)$, real estate 
market $\left(h_{t}+h_{1, t}+h_{2, t}=1\right)$, market of goods $\left(I_{t}+c_{t}+c_{1, t}+c_{2, t}=Y_{t}\right)$ and credit market $\left(b_{t}+b_{1, t}+b_{2, t}=0\right)$. The model assumes the effect of monetary shocks $\left\{e_{R, t}\right\}$, technological shocks $\left\{e_{A, t}\right\}$, property demand shocks $\left\{e_{j, t}\right\}$, cost shocks $\left\{e_{u, t}\right\}$ and shocks in investment $\left\{e_{I, t}\right\}$. The sequence of stochastic shocks $\left\{e_{y, t}\right\}$ is added to the equation of the market-clearing condition (according to Hloušek (2012)). This sequence helps to capture other effects in the economy that are caused by fiscal measures or foreign trade policy when these effects are not explicitly captured in the structure of the model used. Shocks are modelled as the $A R(I)$ process.

\section{Estimation and model verification}

Regarding the parameter setting, we can divide all model parameters into two groups. In one group, the parameters are calibrated; the second group consists of the parameters estimated by applying the Bayesian estimation techniques. The calibrated parameters are summarized in Table 1.

Table 1: Overview of calibrated parameters

\begin{tabular}{|l|c|c|}
\hline Description & Parameter & Value \\
\hline Discount factor: patient households & $\beta_{1}$ & 0.99 \\
Discount factor: Impatient households & $\beta_{2}$ & 0.95 \\
Discount factor: firms & $\gamma$ & 0.98 \\
Labour supply aversion & $\eta$ & 1.01 \\
Housing weight & $j$ & 0.1 \\
Capital output ratio & $\mu$ & 0.3 \\
Elasticity of output to real estate & $v$ & 0.05 \\
Depreciation rate of physical capital & $\delta$ & 0.05 \\
Retail markup & $X$ & 1.1 \\
\hline
\end{tabular}

Source: Authors' construction

Calibrated values of parameters are based on the original article by Iacoviello (2005) and also on Hloušek (2012) and Reichel (2015). Values chosen for the standard deep structural parameters $\left(\beta_{1}, \delta, \mu, X, \eta\right)$ correspond to their setting in the literature dealing with the New Keynesian DSGE models for business cycle fluctuations (see e.g. Galí, 2008). For the parameters $\beta_{2}, \gamma, j$ and $v$, we again drew on the article Iacoviello (2005). For instance, discount factor for impatient households, $\beta_{2}$, is set to a smaller value compared to the discount factor for the patient households, $\beta_{1}$. This guarantees that impatient households cannot act as creditors. Specifically, the value of parameter $\beta_{2}=0.95$ reflects the worse discounting capacity of impatient households, than that of patient households, where $\beta_{1}=0.99$. Similar setting of these parameters can be found in Tonner and Brůha (2014), in addition, authors in this contribution discuss the interpretation of the relatively small difference between the discount factors. Considering that in Tonner and Brůha (2014) the 
focus is to model an open economy; they explain this little difference as a consequence of the ability of patient households to draw loans from abroad and then mediate them to domestic impatient households. The parameter $v$ is, based on Hloušek (2012), calibrated to 0.05 , which corresponds to a relatively small weight of the share of real estate on production and parameter $j$ is set to 0.1 as in Iacoviello (2005).

The second group of parameters is estimated using Bayesian econometric techniques. The Bayesian framework combines maximum likelihood estimation with prior information about parameters, and thus allows us to obtain the posterior probability distribution of the parameters. The model is estimated using quarterly data for the Czech economy; the time series used are described in Table 2. Namely, we use quarterly data for real gross domestic product, consumption in real terms, investment, $C P I$, offer prices of apartments and 3-month interest rate PRIBOR, from The Czech Statistical Office (CZSO) and The Czech National Bank (CNB). All of the time series, except the interest rate, are transformed using logarithmic transformation and then decomposed into cyclical and trend component using the Hodrick-Prescot filter. For the estimation, we use two different data samples. The first data sample is defined by the period starting from the first quarter of 1998 (1998:Q1) until the fourth quarter of 2017 (2017:Q4), therefore covering the entire available period. The year 1998 as a start of the data sample is typically used for the estimation based on the Czech data, see Hloušek (2012), Hloušek (2016) and Tonner and Brůha (2014). The second estimation period spans from the first quarter of 2006 (2006:Q1) and ends with the fourth quarter of 2017 (2017:Q4). These two estimation periods are chosen to allow for the comparison of resulting estimated parameter values and thus to verify the robustness of the results since one can expect that the real estate market has become a competitive market structure only after 2006.

Table 2: Data

\begin{tabular}{|c|l|c|c|}
\hline Variable & Description & Source & Transformation \\
\hline$Y$ & Real gross domestic product & CZSO & $\log , \hat{Y}$ \\
$C$ & Real consumption & CZSO & $\log , \hat{C}$ \\
$I$ & Investment & CZSO & $\log , \hat{I}$ \\
$C P I$ & Consumer Price Index & CZSO & $\log , \widehat{C P I}$ \\
$H P$ & Offer prices of apartments adjusted for inflation & CZSO & $\log , \widehat{H P}$ \\
$R$ & $3 M$ PRIBOR & CNB & $\hat{R}$ \\
\hline
\end{tabular}

Source: Authors' construction

In the first estimation step, parameters for prior densities were chosen. Similarly to calibrated parameters, prior information is set following Iacoviello (2005) and Hloušek (2012), with minor revisions based on the more recent contributions, namely Tonner and Brůha (2014), Hloušek (2016) and Guerrieri and Iacoviello (2017). Values for prior density parameters are summarized in Table 3. 
Table 3: Prior distribution

\begin{tabular}{|c|c|c|c|c|}
\hline & & \multicolumn{3}{|c|}{ Prior distribution } \\
\hline Parameter & Description & Distribution & Mean & Std. dev. \\
\hline \multicolumn{5}{|l|}{ Production } \\
\hline$\alpha$ & Proportion of patient households & Beta & 0.60 & 0.10 \\
\hline$\psi$ & Investment adjustment costs & Normal & 2.00 & 0.50 \\
\hline \multicolumn{5}{|l|}{ LTV ratios } \\
\hline$m_{1}$ & LTV firms & Beta & 0.80 & 0.10 \\
\hline$m_{2}$ & LTV impatient households & Beta & 0.80 & 0.10 \\
\hline \multicolumn{5}{|c|}{ Calvo parameter } \\
\hline$\theta$ & Price rigidity & Beta & 0.75 & 0.10 \\
\hline \multicolumn{5}{|c|}{ Monetary rule } \\
\hline$r_{\pi}$ & Inflation weight in monetary rule & Normal & 0.60 & 0.10 \\
\hline$r_{R}$ & Interest rate weight in monetary rule & Normal & 0.80 & 0.10 \\
\hline \multicolumn{5}{|c|}{ Persistence of shocks } \\
\hline$\rho_{u}$ & Cost-push shock persistence & Beta & 0.70 & 0.10 \\
\hline$\rho_{j}$ & Housing preference shock persistence & Beta & 0.70 & 0.10 \\
\hline$\rho_{A}$ & Technology shock persistence & Beta & 0.70 & 0.10 \\
\hline$\rho_{i}$ & Investment shock persistence & Beta & 0.70 & 0.10 \\
\hline \multicolumn{5}{|c|}{ Volatility of shocks } \\
\hline$\sigma_{R}$ & Monetary shock & Inv. gamma & 0.10 & inf \\
\hline$\sigma_{u}$ & Cost-push shock & Inv. gamma & 0.10 & inf \\
\hline$\sigma_{j}$ & Housing preference shock & Inv. gamma & 0.10 & inf \\
\hline$\sigma_{A}$ & Technology shock & Inv. gamma & 0.10 & $\inf$ \\
\hline$\sigma_{i}$ & Investment shock & Inv. gamma & 0.10 & $\inf$ \\
\hline$\sigma_{Y}$ & Shock depicting other effects in the economy & Inv. gamma & 0.001 & inf \\
\hline
\end{tabular}

Source: Authors' construction

The proportion of the patient households on total population is a priori set to value $\alpha=0.6$, this can be interpreted in a way that we assume that the patient households account for $60 \%$ of the total labor supply. Parameter $\psi$, which denotes investment adjustment costs, is set to 2. This corresponds to a rather high adjustment cost. Parameters $m_{1}$ and $m_{2}$ describe LTV ratios and are both set to the equal value $m_{1}=m_{2}=0.8$. Parameter $\theta$ represents the proportion of firms that cannot set prices, its prior setting is in line with the value commonly used in literature, $\theta=0.75$. Parameters in the monetary rule and those describing properties of the exogenous shocks are set to standard values based on previous empirical studies dealing with the Czech economy. 
We obtain posterior densities of the model parameters using a Metropolis-Hastings algorithm with 1000000 samples, using two chains with 500000 replications for each. In order to ensure convergence of the system, first $40 \%$ of all samples are discarded. As a diagnostic measure to evaluate the overall convergence, the multivariate convergence diagnostic by Brooks and Gelman (1998) is used. Results from the posterior estimation for each of the before mentioned data samples can be found in Table 4. For some parameters, the posterior value does not diverge from its prior information. On the other hand, for some parameters, we can find apparent structural change given the substantial difference between posterior characteristics for each of the two data samples.

Table 4: Posterior distribution

\begin{tabular}{|c|c|c|c|c|c|c|}
\hline \multirow{4}{*}{$\frac{\text { Parameter }}{\alpha}$} & \multicolumn{6}{|c|}{ Posterior distribution } \\
\hline & \multicolumn{3}{|c|}{ 1998:Q1-2017:Q4 } & \multicolumn{3}{|c|}{ 2006:Q1-2017:Q4 } \\
\hline & \multirow{2}{*}{$\begin{array}{l}\text { Mean } \\
0.3268\end{array}$} & \multicolumn{2}{|c|}{95 HPDI } & \multirow{2}{*}{$\begin{array}{l}\text { Mean } \\
0.4848\end{array}$} & \multicolumn{2}{|c|}{ 95\% HPDI } \\
\hline & & 0.2156 & 0.4327 & & 0.3559 & 0.6160 \\
\hline$m_{1}$ & 0.4471 & 0.3143 & 0.5821 & 0.8035 & 0.7252 & 0.8829 \\
\hline$m_{2}$ & 0.7320 & 0.6283 & 0.8368 & 0.5931 & 0.4299 & 0.7597 \\
\hline$\theta$ & 0.7495 & 0.5922 & 0.9119 & 0.7485 & 0.5937 & 0.9147 \\
\hline$\psi$ & 0.1067 & 0.0454 & 0.1643 & 0.3191 & 0.2174 & 0.4164 \\
\hline \multicolumn{7}{|c|}{ Monetary rule } \\
\hline$r_{\pi}$ & 0.5500 & 0.3798 & 0.7190 & 0.6047 & 0.4418 & 0.7643 \\
\hline$r_{R}$ & 0.9355 & 0.9214 & 0.9502 & 0.9203 & 0.8985 & 0.9427 \\
\hline \multicolumn{7}{|c|}{ Persistence of shocks } \\
\hline$\rho_{u}$ & 0.9547 & 0.9306 & 0.9793 & 0.7527 & 0.6435 & 0.8628 \\
\hline$\rho_{j}$ & 0.9028 & 0.8651 & 0.9410 & 0.9354 & 0.8917 & 0.9792 \\
\hline$\rho_{A}$ & 0.7565 & 0.6740 & 0.8412 & 0.7396 & 0.6282 & 0.8551 \\
\hline$\rho_{i}$ & 0.6463 & 0.5604 & 0.7301 & 0.6043 & 0.5155 & 0.6918 \\
\hline \multicolumn{7}{|c|}{ Volatility of shocks } \\
\hline$\sigma_{R}$ & 0.0017 & 0.0014 & 0.0020 & 0.0020 & 0.0015 & 0.0024 \\
\hline$\sigma_{u}$ & 0.0141 & 0.0100 & 0.0181 & 0.0057 & 0.0039 & 0.0076 \\
\hline$\sigma_{j}$ & 0.3348 & 0.2169 & 0.4521 & 0.2166 & 0.0875 & 0.3402 \\
\hline$\sigma_{A}$ & 0.0167 & 0.0137 & 0.0195 & 0.0080 & 0.0045 & 0.0113 \\
\hline$\sigma_{i}$ & 0.0380 & 0.0327 & 0.0431 & 0.0392 & 0.0321 & 0.0463 \\
\hline$\sigma_{Y}$ & 0.0010 & 0.0002 & 0.0019 & 0.0225 & 0.0137 & 0.0310 \\
\hline
\end{tabular}

Source: Own calculation

The proportion of patient representative households is a priori assumed to be $\alpha=0.6$. Its posterior estimate for the entire period is 0.32 and for the shorter data span $\alpha=0.48$. 
Given the estimated highest posterior density intervals (HPDI), we can conclude that these estimates are statistically significantly different. If we compare the obtained results with their corresponding value as it is presented in the original paper by Iacoviello (2005), we see that the result for the shorter data span is closer to this value. According to Iacoviello (2005) estimate of $\alpha$, the patient households account for $64 \%$ of the total population. This difference between the estimates supports our initial hypothesis that the Czech housing market fully developed only in the later years around 2006. Both values, at the same time, support the importance of the existence of households facing credit constraints. If we take into account the point estimates, then the estimated proportion of households facing credit constraints is $78 \%$ for the entire period and $62 \%$ for the period after 2006.

Parameter $m_{1}$ and $m_{2}$ represent LTV for firms and impatient households respectively, and they are both set to value 0.8 , i.e., a debtor can receive a loan for up to $80 \%$ of the value of the property. Posterior distributions are again different for both periods examined. For a more extended period, LTV for firms is lower than the LTV for impatient households. This result indicates that households have better access to mortgage loans than firms and can receive higher loans for the property with the same value. This is not in line with the conclusions in the original article by Iacoviello (2005); however, it corresponds to the estimates presented in Hloušek (2012) and Reichel (2015). On the other hand, for a shorter data sample, we get results similar to the original work of Iacoviello (2005). For comparison, Iacoviello (2005) estimated LTV for firms at 0.89 and households at 0.55 . Hence, the ability to obtain funding from the real estate collateral is higher for the firms. These results are not surprising given the historical development of the Czech real estate market. From the obtained results, we can abstract the information indicating that the model better describes the situation in the Czech economy after the year 2006.

The posterior estimate of the parameter $\theta$ does not differ significantly from the prior density on both data samples, and thus, the data do not provide any new information about this parameter. For this reason, Iacoviello (2005) and Hloušek (2012) calibrate this parameter. The estimate of parameter $\psi$, compared to the prior information, has a relatively small value, both for the longer and the shorter period. Iacoviello (2005) again calibrates this parameter. Hloušek (2012) presents a significantly higher parameter estimate equal to 2.94. The differences in the results compared to Hloušek (2012) may be due to the choice of the period, mainly for two reasons (i) the shorter evaluated time period (ii) the period when the housing market in the Czech Republic faced the transition from non-market structure to fully competitive market structure.

The parameters characterizing the monetary rule are estimated with standard values and correspond to empirical studies estimated at the Czech economy, see e.g., Hloušek (2012). Concerning the exogenous shocks, they all show a relatively strong persistence and the model's ability to identify this persistence, along with their volatility, very well. The highest persistence in both periods is shown by shock $\rho_{j}$, describing household housing preferences. This shock is also the most volatile one (see $\sigma_{j}$ ) and this holds for both periods.

Given the historical development of the housing market in the Czech Republic and complying with the original article, the results for the shorter data sample are preferably 
better describing the Czech housing market. The point estimates from this period serve as a benchmark for subsequent simulations of alternative LTV scenarios.

\section{Results}

At this point, we will focus on analyzing the model dynamics through the lens of impulse response functions to monetary shock. We will discuss alternative settings of the LTV and the response of main model variables to the monetary shock. Discussing the alternative settings of the LTV allow us to understand how to set the optimal LTV concerning the business cycle phase and corresponding monetary policy. In the first step, we simulate three alternative scenarios that help us to analyze model dynamics. In this case, the change in LTV will consider the impatient households only. In the second step, we adjust the scenarios to consider the model responses to changes of LTV for both the impatient households and firms. In the third step, we evaluate the effects of all possible LTV settings through the maximum deviations of variable trajectories from their steady-state values.

Figure 2 shows the response of modelled variables to monetary shock. We are focusing on the effect of monetary restriction, i.e. the effect of nominal interest rate change by one standard deviation. The $x$-axis represents the quarters following the initial monetary shock. The $y$-axis expresses the percentual change of the model variable from its steady-state. The impulse-response function based on the estimated mean parameter values is denoted as "Benchmark". Alternative scenarios where the levels of LTV for households correspond to the extreme values are denoted as "No collateral" and "High collateral" respectively. In the case of "No collateral" scenario, the value of LTV is set at a low value $\left(m_{2}=0.05\right)$, and in the case of "High collateral" scenario, this value is set at a high value $\left(m_{2}=0.95\right)$. As for the interpretation itself, a temporary rise in interest rates in the "Benchmark" setting implies the fall of both inflation and house prices by $1.1 \%$ where the output falls by $5 \%$. The response of total consumption exhibits a decrease of $2.4 \%$. By looking at the consumption of patient and impatient households, one can observe its immediate decrease by $5.8 \%$ for the impatient households and by $0.45 \%$ for the patient households. According to Hloušek (2016), the difference between the responses of patient and impatient households is due to two causes. The first one is based on the ability of the credit constraint to be binding because of the decline in house prices. The second cause relates to Fischer debt-deflation effect, where an unexpected fall in inflation triggers the rise of ex-post real interest rates and real debt burden. The wealth is thus transferred from the borrowers to the creditors. The scenario considering the higher probability of borrowing ("High collateral") implies the accelerating responses of analyzed model variables. Figure 2 clearly shows a more profound decline in output (by $9 \%$ ), inflation (by 2.2\%) and consumption (by 5.2\%). We can also observe a sharp decline in total consumption of impatient households. This decline can be explained primarily by the Fischer debt-deflation effect, where the fall in inflation is considerably higher (in comparison with the "Benchmark" scenario.

In the case where impatient households do not have access to credits ("No collateral" scenario), the response to monetary restriction is very similar to the previous scenarios. However, the decline in the consumption of impatient households is relatively modest. 
Figure 2: Impulse-response of monetary shocks based on alternative LTV settings for households

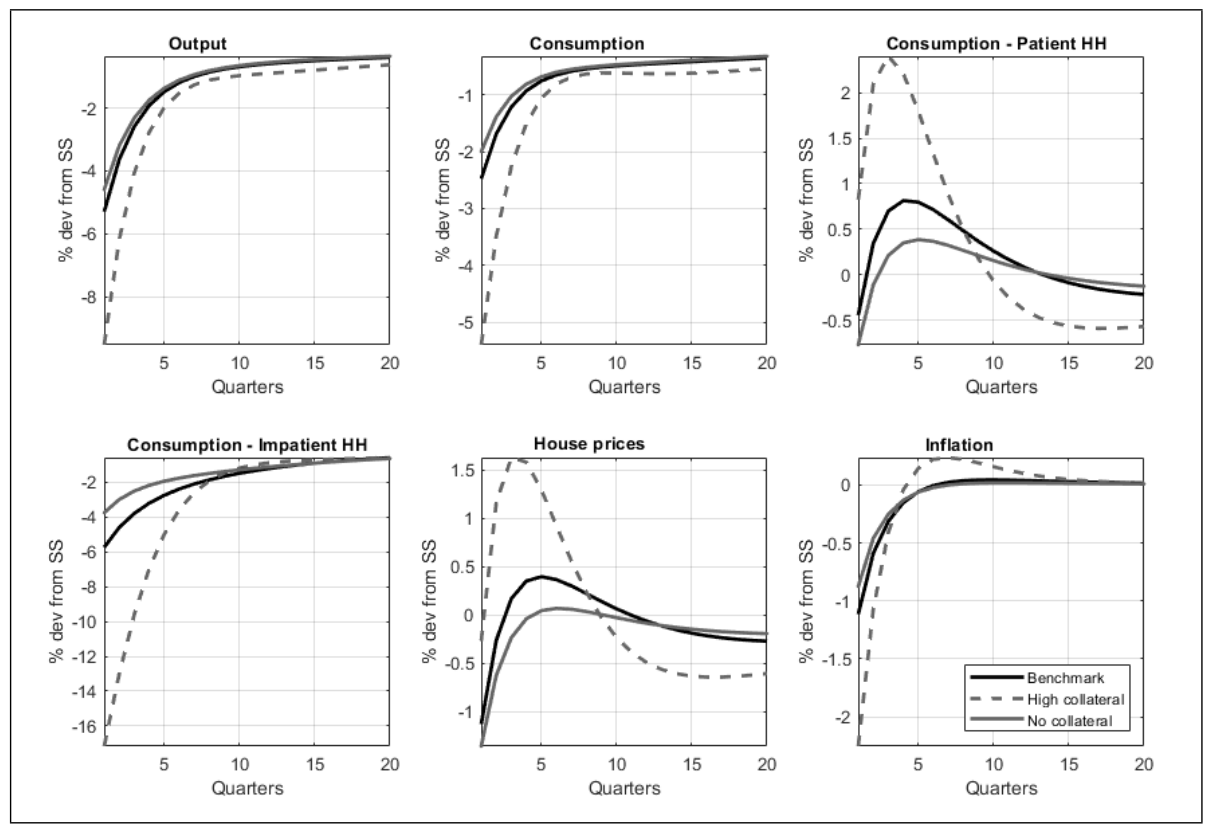

Source: Authors' construction based on model IRFs.

Figure 3 depicts the responses modelled variables to monetary shock in case of LTV changes for both the households and firms. The "Benchmark" denotes the setting that corresponds to the mean parameter values based on the estimated models. The scenario "No collateral" reflects the low values of LTV values for firms and impatient households $\left(m_{1}=0.05\right.$ and $\left.m_{2}=0.05\right)$. On the contrary, the second scenario, denoted as "High collateral", corresponds to the setting with very high values of LTV for firms and impatient households $\left(m_{1}=0.95\right.$ and $\left.m_{2}=0.95\right)$.

The responses of the benchmark scenarios are like those presented in Figure 2. We will thus focus on alternative scenarios. Monetary restriction in both scenarios makes the future consumption cheaper. Economic agents should, therefore, respond in a way that reduces the loan amount. This reduction affects individual levels of consumption. The "No collateral" scenario shows negligible deviations in almost all variables. The reason for such weak responses lies in strong constraints at the credit market that do not allow impatient households and firms to smooth their consumption over time. The impact of the monetary shock in this credit-constrained economy is thus minimal. The initial responses of consumption and output lead to decreases by $1.1 \%$ and $2 \%$ respectively.

On the other hand, the "High collateral" scenario simulates an economy with very weak or almost non-existent credit market constraints. The responses of the economic agent to the monetary policy shocks are thus stronger. Impatient households perceive the positive effects of future consumption and therefore immediately reduce the credit 
amount and consumption (Figure 3 shows a $25 \%$ decrease in consumption). The reduction in consumption of impatient households is also induced by the Fischer debt-deflation effect caused by the fall in inflation. Patient households that have so far funded the loans to the impatient households find out the reduced demand for credits. As a result, their consumption rises. These opposite effects result in an $8 \%$ reduction in overall consumption and a $16 \%$ decrease in output relative to their steady-state values.

Figure 3: Impulse-response of monetary shocks based on alternative LTV settings for households and firms

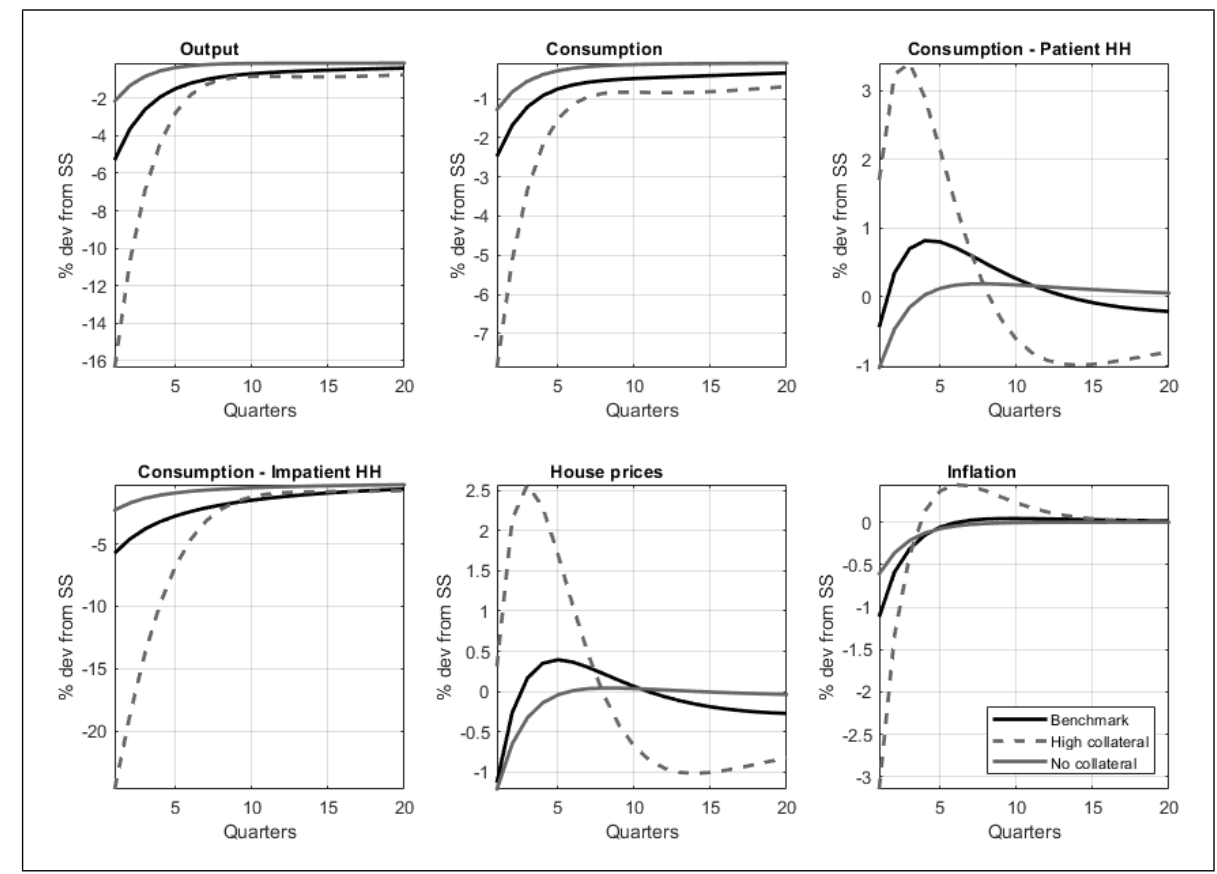

Source: Authors' construction based on model IRFs

Figure 4 shows the maximum deviations in impulse responses functions of model variables to monetary shock at different settings of LTV of impatient households. On the $x$-axis, one may find the level of LTV. The $y$-axis indicates the maximum (negative) deviation of the impulse response from the steady-state. We are focusing on negative deviation because the responses to the restrictive shock were negative for all investigated variables at different LTV level settings (see Figure 2). Figure 4 provides evidence of a non-linear relationship between individual variables and the level of LTV. Similar conclusions offer Hloušek (2016). The presented curves prove that more benevolent lending behaviour (that may be associated with high values of LTV) augments the adverse effects of the restrictive monetary policy on the economy. More restrictive requirements for credits allow the central banks to smooth the business cycles with lower amplitudes. 
Figure 4: Amplitudes' sensitivity of the impulse response of monetary shocks based on alternative LTV settings for inpatient households

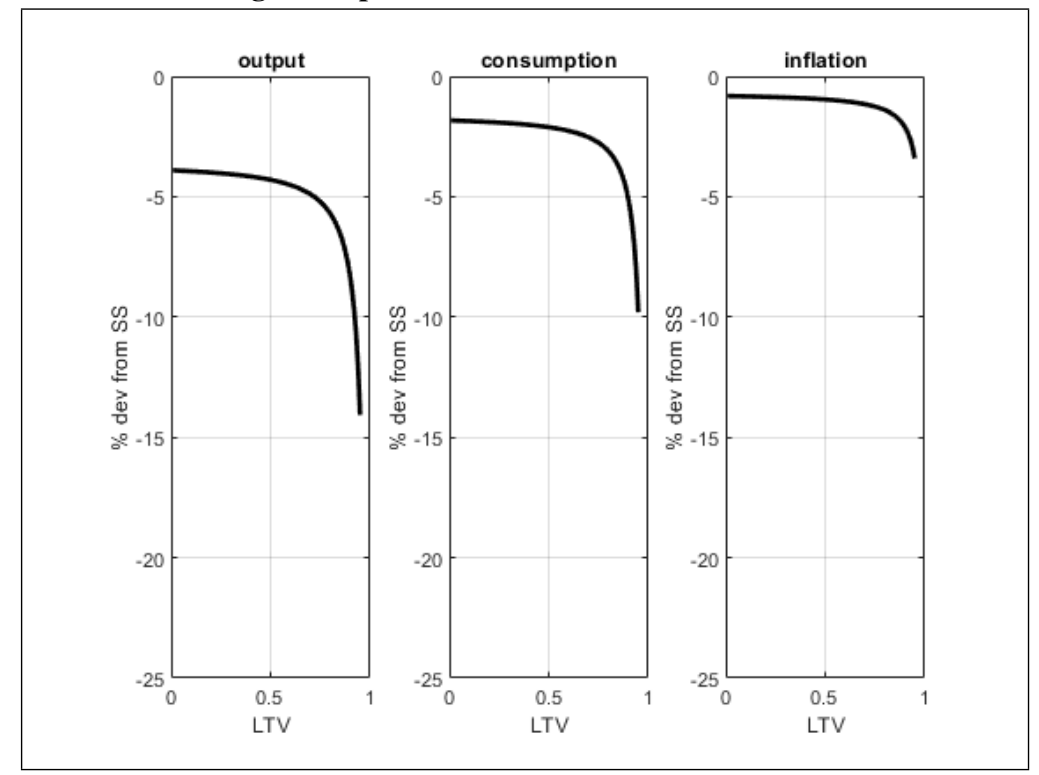

Source: Authors' construction based on model IRFs

Figure 5: Amplitudes' sensitivity of the impulse response of monetary shocks based on alternative LTV settings for inpatient households and firms

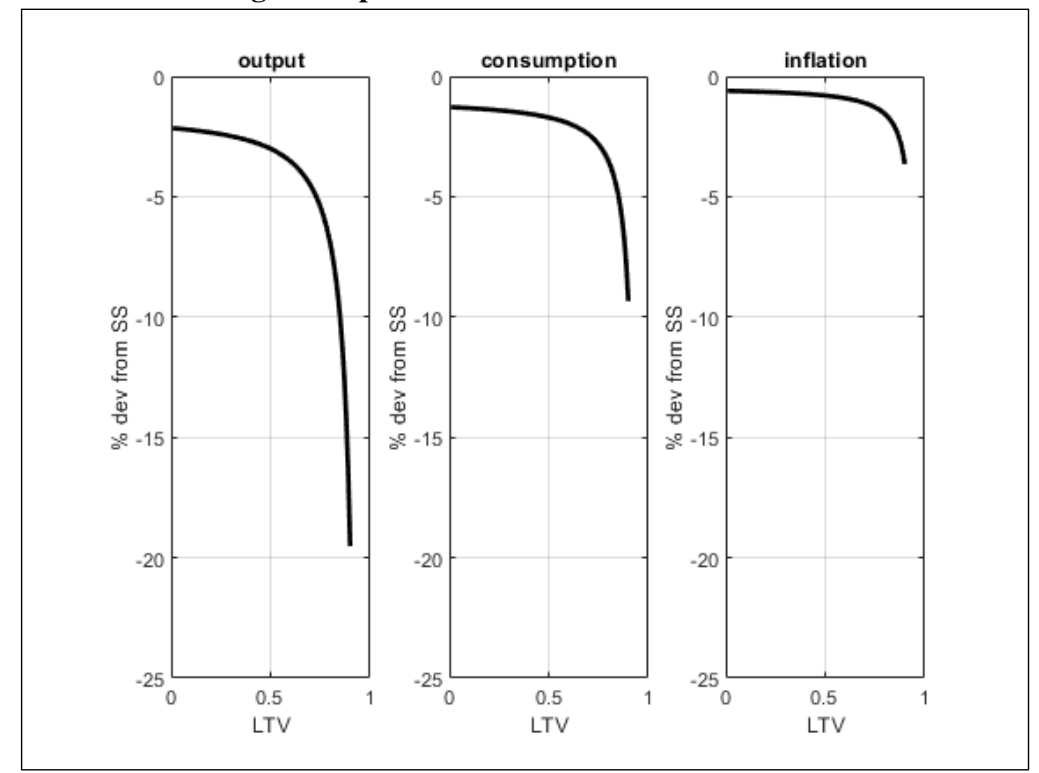

Source: Authors' construction based on model IRFs 
Figure 5 shows the maximum deviations in impulse responses functions of model variables to monetary shock at different settings of LTV of impatient households and firms. The difference from Figure 4 lies in releasing of the parameter $m_{1}$. This parameter is now set to a value comparable to the parameter $m_{2}$. The analysis allows us to discuss the magnitude of the impact of restrictive monetary policy on an economy where impatient households and firms have comparable borrowing conditions. When comparing Figure 4 and Figure 5, the maximum responses of key macroeconomic variables differ mainly in their magnitude. Our results are thus robust, and we can provide strong evidence of a non-linear relationship between the dynamics of the model variables and the size of LTV parameters.

The outcomes of this analysis are following the findings provided by Walentin (2014) and Hloušek (2016). The restrictive monetary policy is effective in reducing inflation at higher levels of LTV. However, this higher efficiency is accompanied by higher economic and welfare costs lying in a considerably sharper drop in real economic performance expressed by the fall in output and consumption.

\section{Conclusion}

The paper aimed to estimate the DSGE model with the housing sector and to simulate the impacts of restrictive monetary policy based on alternative scenarios of LTV settings. We used the model proposed by Iacoviello (2005). It contains restrictions on the credit market and allows us to simulate the impacts of monetary policy. Using the data for the Czech Republic, we have estimated the model for the full and shorter period. Using a full data set led to bias in parameter estimates. These findings correspond to the economic situation of housing sector of the Czech Republic, where the full market structure corresponding to the model equations in the model of Iacoviello (2005) can only be considered since 2006. Our simulations of alternative LTV setting for households and firms have been carried out by using the mean values of the estimated parameter on the shorter period. The effects of monetary policy shock were found to be non-linear, depending on the size of the LTV. This finding has two important implications for monetary policy. Firstly, the LTV seems to be a promising tool of the unconventional and macroprudential monetary policy limited by the environment of almost zero or negative interest rates. Secondly, the restrictive monetary policy is more efficient in reducing inflation at the higher levels of the LTV than at the lower levels. It means that this policy can soften inflation pressures and secure the banking sector by imposing restrictions on the mortgage loan market. This policy is implemented as recommendations of the Czech National Bank to the Czech banking sector since 2015 (see CNB, 2019) to reduce systemic risks in the financial sector. This kind of risk may be a result of relaxed credit standards by mortgage banks, growth property prices, and fast expansion in the value of loans secured by residential property in an expansionary phase of the financial cycle. However, as our results prove, the efficiency of the policy based on the LTV is accompanied by costs of a sharper decline in economic performance and welfare in comparison with the conventional tools based on interest rate transmission mechanism. 


\section{Acknowledgement/Funding}

This research was funded by funding for specific research at the Masaryk University, Faculty of Economics and Administration, project MUNI/A/0972/2018.

\section{References}

Bracons, A. O. and Rabanal, P. (2010). The drivers of housing cycles in Spain. SERIEs: Journal of the Spanish Economic Association, Springer; Spanish Economic Association, vol. 1(1), 101-130.

Brooks, P. S. and Gelman A. (1998) General Methods for Monitoring Convergence of Iterative Simulations. Journal of Computational and Graphical Statistics, 7(4), 434-455. Christensen, I., Corrigan, P., Mendicino, C. and Nishiyama, S-I. (2016). Consumption, housing collateral and the Canadian business cycle. Canadian Journal of Economics. Canadian Economics Association. 49(1), 207-236.

CNB. (2019). Recommendation on the management of risks associated with the provision of retail loans secured by residential property. Available on: https://www.cnb.cz/en/financialstability/macroprudential-policy/recommendation-on-the-management-of-risks-associated-with-the-provision-of-retail-loans-secured-by-residential-property/.

ECB. (2019). European Central bank: Macroprudential policy strategy. Available on: https://www.ecb.europa.eu/ecb/tasks/stability/strategy/html/index.cs.html.

Funke, M., Kirkby, R. and Mihaylovski, P. (2018). House prices and macroprudential policy in an estimated DSGE model of New Zealand. Journal of Macroeconomics, Elsevier, 56(C), 152-171.

Funke, M. and Paetz, M. (2012). A DSGE-based assessment of nonlinear loan-to-Value policies: Evidence from Hong Kong. BOFIT Discussion Papers 11/2012. Bank of Finland, Institute for Economies in Transition.

Gali, J. (2008). Monetary policy, inflation, and the business cycle: an introduction to the new Keynesian framework. Princeton: Princeton University Press.

Guerrieri, L, and Iacoviello M. (2017). Collateral Constraints and Macroeconomic Asymmetries. Journal of Monetary Economics, 90, 28-49.

Hloušek, M. (2012). DSGE model with collateral constraint: estimation on Czech data. Proceedings of 30th International Conference Mathematical Methods in Economics. Karviná: Silesian University, School of Business Administration, 296-301.

Hloušek, M. (2016). An Estimated DSGE Model with a Housing Sector for the Czech Economy. Statistics and Economy Journal. Prague: Czech Statistical Office, 96(4), 37-55. Iacoviello, M. (2005). House Prices, Borrowing Constraints and Monetary Policy in the Business Cycle. American Economic Review, 95(3), 739-764.

Iacoviello, M. and Neri, S. (2010). Housing Market Spillovers: Evidence from an Estimated DSGE Model. American Economic Journal: Macroeconomics, 2, 125-164.

Kannan, P., Rabanal, P., and Scott A. M. (2012). Monetary and Macroprudential Policy Rules in a Model with House Price Booms. The B.E. Journal of Macroeconomics, 12(1). Kiyotaki, N. and Moore, J. (1997). Credit Cycles. Journal of Political Economy, 105(2), 211-48. 
Mendicino, C., Punzi, M. T. (2014). House prices, capital inflows and macroprudential policy. J. Bank. Finan, 49, 337-355.

Reichel, V. and Hloušek, M. (2015). Asymmetric behaviour of collateral constraint: applications on the Czech economy. Proceedings of 33nd International Conference Mathematical Methods in Economics. Plzeň: University of West Bohemia, pp. 707-712. Robinson, T. and Robson, M. (2012). Housing and financial frictions in a small open economy. Reserve Bank of Australia

Tonner, J. and Brůha, J. (2014). The Czech Housing Market through the Lens of a DSGE Model Containing Collateral-Constrained Households. Working Papers 2014/09. Czech National Bank.

Walentin, K. (2014). Housing Collateral and the Monetary Transmission Mechanism. Scandinavian Journal of Economics, Wiley Blackwell, 116(3), 635-668. 